\title{
Does intermediate tariff bode well for trade integration in ECOWAS?
}

\author{
Olusegun Barnabas Obasaju \\ Economics Department, Landmark. University, \\ Nigeria \\ obasaju.barnabas@lmu.edu.ng \\ Wumi Kolawole Olayiwola \\ Economic Policy Analysis Unit, ECOW AS Commission, \\ Nigeria \\ kolayinola@gmail.com \\ Henry Okodua \\ Economics Department, Covenant University, \\ Nigeria \\ benry.okodua@covenantuniversity.edu.ng \\ Ruth Uzoaku Obasaju \\ Economics Department, Kwara State University, \\ Nigeria \\ ruthobasaju@gmail.com
}

Abstract. This paper analyses the impact of intermediate tariffs on intraregional intermediate exports within the Economic Community of West African States (ECOWAS) from 2000 to 2015. This is in order to investigate whether or not the levels of intermediate tariffs bode well for trade integration in ECOWAS. Using the Heckman Two-step technique, the empirical estimates reveal that the similarities in GDP and the presence of the West African Economic and Monetary Union (WAEMU), among others, are highly significant determinants of intraregional intermediate exports in ECOWAS. Contrarily, the quality of institution and the levels of intermediate tariffs are not important contributors to intraregional exports of intermediates. As the continent prepares towards the implementation of the African Continental Free Trade Area and considers regional value chains quintessential to development, policy makers should be informed of the unsupportive levels of intermediate tariffs in ECOWAS- a regional economic community that accounts for about thirty percent of the African population. Trade policies targeted at lowering intermediate tariffs within ECOWAS are called for.

\footnotetext{
Received:

July, 2018

1st Revision:

August, 2018

Accepted:

November, 2018

DOI:

10.14254/2071

8330.2018/11-4/14
} 
Keywords: intermediate tariffs, trade integration, regional value chains, Heckman two-step, ECOWAS.

JEL Classification: F10, F13, F14, F15, C30, C33

\section{INTRODUCTION}

The Economic Community of West African States (ECOWAS) is a REC that not only has the largest economy in Africa - Nigeria - as her member, it also accounts for about 30 percent of the African population. In essence, using this REC as a case study is worthwhile. In ECOWAS, the ECOWAS Trade Liberalisation Scheme is saddled, among others, with the responsibility of clearing tariff and non-tariff barriers to trade within the sub-region. ETLS is a comprehensive trade liberalisation programme put in place early in the existence of ECOWAS. Its implementation was finally launched in 1990 and was meant to occur in different stages: (1) Immediate and full liberalisation of unprocessed goods and traditional handicrafts' trade. 2) Trade in industrial products was meant to be liberalised in phases with the phasing reflective of the developmental stage of the three groups of ECOWAS Member States. Group 1 consists of Cape Verde, Guinea Bissau, The Gambia, Burkina Faso, Mali and Niger; group 2 - Benin, Guinea, Liberia, Sierra Leone and Togo; group 3 - Ivory Coast, Ghana, Nigeria and Senegal. ETLS was aimed at progressively reducing and later eliminating all tariff and non-tariff barriers against intra-ECOWAS trade (ECOWAS Vanguard, 2013). It is expected that ETLS would be supportive of trade within the ECOWAS region through its drive towards the elimination of tariff and non-tariff barriers to trade, among others (ECOWAS Vanguard, 2013).

Based on the availability of data on intermediate goods on a bilateral level, data from the World Integrated Trade Solution (WITS) Trains database show that intermediate exports face varying tariff charges even within ECOWAS. Figure 1 shows the movements in intermediate tariffs and intraregional intermediate exports. In the whole, the trend analysis suggests that intermediate tariffs and intraregional intermediate exports move in opposite directions for most of the periods. To understand the intermediate tariff charged per country, Figure 2 is instructive. Statistics from WITS show that on the average, The Gambia charged the highest between 2013 and 2015 and that there exists varying degrees of intermediate tariff charges on imports within ECOWAS. On the average, between 2000 and 2015, The Gambia maintained the highest average charge of 14.83 percent in contrast to Senegal which had the lowest average of 6.43 percent. In 2000, The Gambia's charge on Nigeria's intermediate imports was as high as 50 percent, but this trend has changed as the charges by The Gambia have reduced. For example, in 2014, The Gambia's charge on Nigeria and Côte d'Ivoire's intermediate imports were 22.14 percent and 20 percent respectively. Nigeria seems to face the highest intermediate tariff within the region, facing a charge of about 10.2 percent in 2012, 22.44 percent in 2014 and 25.36 percent in 2015 from Benin, Côte d'Ivoire and Ghana respectively. ECOWAS is already a customs union and it is expected that at this stage tariff and non-tariff barriers to trade would have been cleared. 


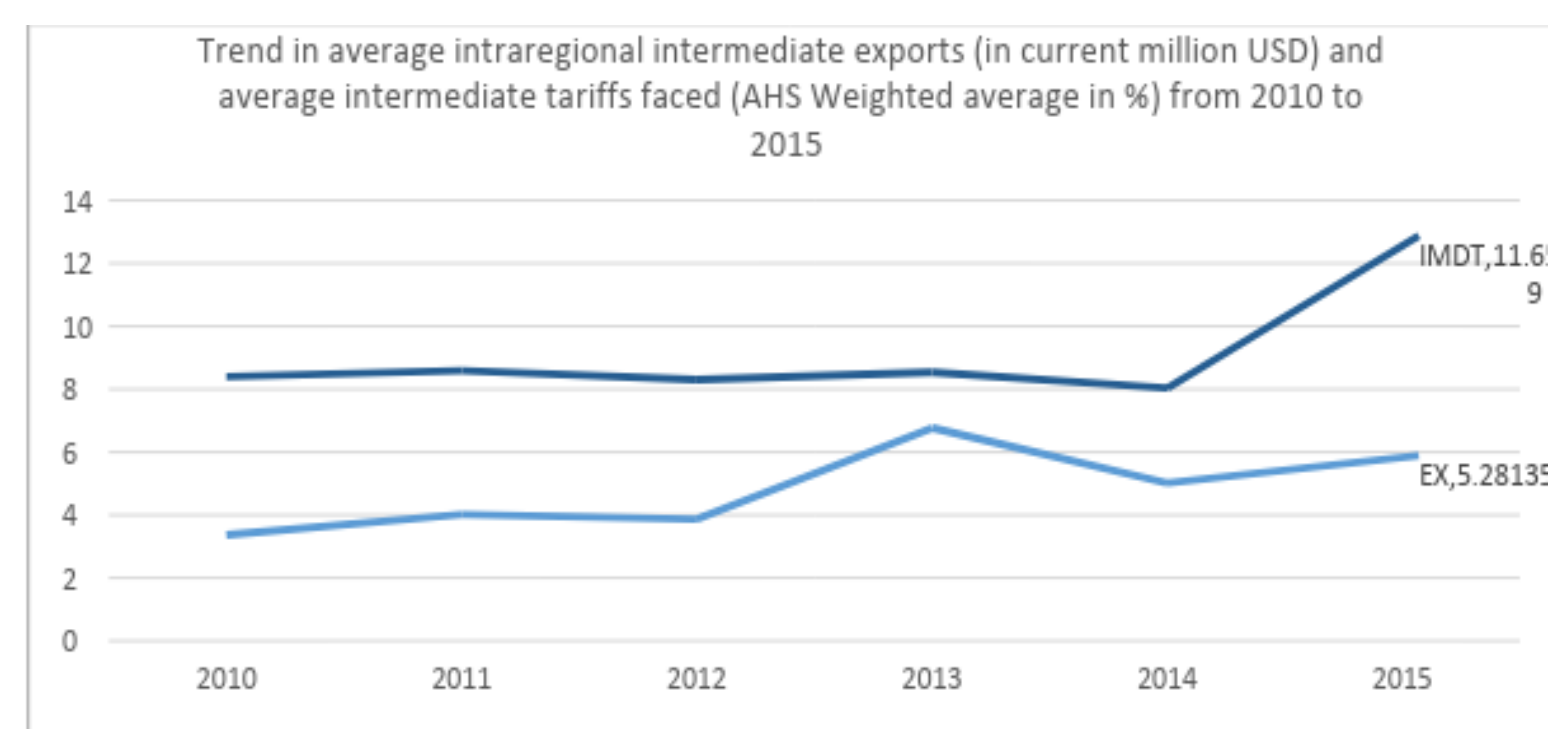

Figure 1. Trend in average intraregional intermediate exports and intermediate tariffs Source and Notes: Authors', compiled from World Integrated Trade Solutions (WITS). IMDT is intermediate tariffs and EX is intra-regional intermediate exports.

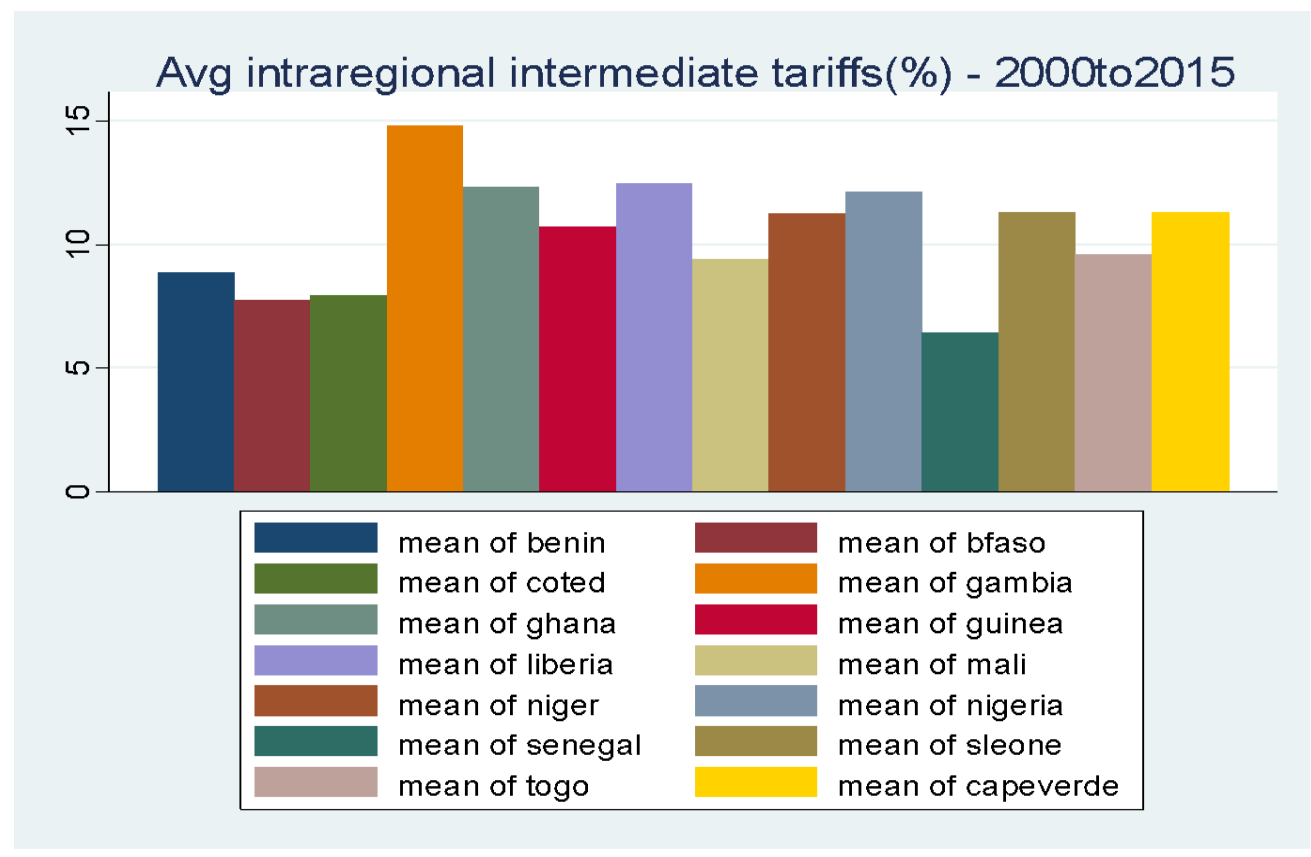

Figure 2. Intra-regional Intermediate Tariffs

(AHS Weighted Average - \%) from 2000 to 2015

Source: Authors', compiled from World Integrated Trade Solutions (WITS).

With the disparate tariffs on intermediates, the motive of this paper is to investigate whether or not intermediate tariff is supportive of intraregional intermediate exports within ECOWAS.

\section{REVIEW OF EMPIRICAL STUDIES}

Olofin, Salisu Ademuyiwa and Owuru (2013) investigated the determinants of a successful regional trade agreement in West Africa between 1995 and 2010. They used the Least Square Dummy Variable 
(LSDV) technique to estimate a modified gravity model which includes the gravity variables of income and distance together with socioeconomic variables such as common language, political stability and infrastructure. They found that economic size, distance, landmass, common border and landlockness of countries influence intraregional exports in ECOWAS significantly. In addition, they found that the West African Economic and Monetary Union (WAEMU) is trade creating while the West African Monetary Zone (WAMZ) is trade diverting. This work very well deals with the roles of WAEMU and WAMZ in intra-regional trade among other objectives of the study. The role of intermediate tariff was however not taken into cognisance in their study and the study is silent on the possible implications of selection bias as a result of dropping prevalent trade flows.

Afolabi, Nor Aznin and Mukhriz (2015) investigated bilateral trade flows and the level of openness in ECOWAS from 1981 to 2013 using a gravity model. They employed PPML, fully modified ordinary least squares (FMOLS) and the canonical cointegrating regression. Adding trade and financial openness variables to the gravity variables, they found that financial openness negatively impacts intra-regional trade flows. The effect of trade openness varied in terms of economic and statistical significance while comparing the different techniques. This study is however silent about the possibility of selection bias and did not control for the presence of RTA. It also differs from this current study in respect of the role of intermediate tariffs faced on intra-regional intermediate exports. Estrella (2012) used 80 percent of dataset on world trade to compare the alternative methods to estimate gravity models of bilateral trade based on bilateral exports for 80 countries. The dataset spanned 1980 to 2008. The techniques compared were Truncated OLS, Tobit, PPML, Heckman, Panel fixed and Panel random models. Following the Anderson and van Wincoop (2003) gravity equation, Estrella (2012) found that the Heckman sample selection model yielded an overall better results than the other techniques.

Lopez-Gonzalez (2012) investigated the impact of a free trade area (FTA) on the value of intermediate imports. Using intermediate imports from the BEC nomenclature and input-output tables for the Trade in Value Added (TiVA) economies, and controlling for the observed endogeneity of free trade agreements using a set of country-year fixed effects, he found that an FTA increases the value of intermediate imports by 25 percent. First, he investigated whether or not the FTA variable is endogenous following the recommendation of Baier and Bergstrand (2007) who noted that if changes in FTA are strictly exogenous to changes in trade flows, it follows that a future FTA, say an FTA+ 5 (i.e. 5 years future FTA), is expected to be uncorrelated with the current trade flow. This is actually a test of reverse causality. After correlating the current FTA with 5 year lead of FTA, he observed a strong correlation between them. Providing controls by using time-varying reporter and partner fixed effects and performing a regression in the presence of the 5 year lead of FTA, the insignificant impact of the five year lead of FTA on current imports showed the appropriateness of the set of fixed effects used in correcting for the endogeneity of FTA.

Kowalski et al. (2015) included intermediate tariff from origin country while examining the determinants of value added trade flows using a gravity model. They controlled for the effect of RTA by using the intermediate coverage of imports (and exports) while using data from the OECD Trade-in Value Added (TiVA) database. Their sub-samples include the high-income and developing countries, but no ECOWAS country is included in the TiVA database. Among other empirical findings, they found that RTAs positively but insignificantly impact bilateral value-added flows in developing countries while intermediate tariffs from the origin country negatively and significantly impacts bilateral value-added flows.

Slany (2017) examined the role of trade policies in building regional value chains in Africa between 2006 and 2012. Using the UNCTAD-Eora GVC database, the author calculated the trade in value added between African countries and evaluated the position of each country in the regional value chain (RVC). The matrix of 'global value added exports' was used to derive the dependent variable. The dependent 
variable used (foreign value added - from the backward integration perspective) is the imported foreign value added from the region embodied in the exports of a given country to that region. The technique adopted is the fixed effects estimator while controlling for auto-correlation and cross-sectional correlation among standard errors. The study found, among others, that tariffs charged on capital goods is the most restrictive to imported foreign value added. Southern Africa was also found to be the most integrated region.

There are notable differences in the focus and approach adopted by Slany (2017) and this current paper. First, the former uses foreign value added flows as the dependent variable and uses this indicator as a measure of backward participation of a country in RVCs. This current study does not investigate the impact of intermediate tariffs on participation in RVCs but rather its impact on intermediate exports with the aim of predicting the implications for regional value chains owing to the important roles of intermediates in international value chains. Second, Slany (2017) was interested in the roles of different tariffs - on raw, intermediate and capital goods but we focus on intermediate tariffs. Third, the former is in respect of Africa while this current study is based on ECOWAS. Fourth, the former is silent on the need to control for the role of regional trade agreements as this play crucial roles on international value chains - be it regional or global. The fifth difference is in the technique adopted, as bilateral trade flows are usually characterized by the preponderance of zeros - this however applies to this current study and not Slany (2017) because of the indicator used by the latter as the dependent variable. Sixth, following from the nature of the dependent variable used by Slany (2017) - foreign value added in exports, which has both an import and export side - tariffs faced and charged are both included in the model. Here, we use intermediate tariffs faced by intermediate exports within ECOWAS.

More recently, Sapkota, Acharya, Minowa and Neupane (2018) examined the trends and determinants of trade integration in Asia. They used the Systems Generalized Method of Moments dynamic panel data technique to investigate the determinants of regional trade integration amongst 34 Asian countries between 1990 and 2015. The study found that economic size (measured by GDP), access to mobile phone (and its concentration) and the rate of urbanization all positively and significantly impacted both total trade and intra-Asian trade volume but exerted an insignificant impact on intra-Asian trade share. They suggested that further trade liberalisation alongside policies needed to boost domestic and regional trade are called for.

\section{METHODOLOGY}

\subsection{Methodology and estimation techniques}

Following the seminar paper of Anderson (1979) that gave the gravity model a sound theoretical underpinning, the gravity model has become the major workhorse of trade theorists. A direction-specific trade, the value of the intraregional intermediate exports is the dependent variable here. Before specifying the base model, insights from the theory is crucial. Proponents of the New Trade Theory (NTT) posit that this theory explains why it is possible for countries which are reasonably different, in absolute terms, in factor endowments, to engage in trade. Hence, the coefficient of this variable is expected to be negative. This follows from the reasoning that the upstream stages of the value chain (like supply of raw inputs) may be performed by countries that may be more labour intensive while the downstream stages (like branding) may be performed by more capital or technologically- intensive countries. Similarly, NTT explains why countries with similar GDPs can engage in trade. In essence, NTT predicts that trade flows is a positive function of similarities in GDP.

To capture the differences in factor endowments, the ratio of capital to labour force is used reflecting the distance between the exporting and importing countries in respect of relative factor endowments 
(Wang, Wei \& Liu, 2010). Due to the rarity of data on the actual labour employed, the labour force (which may incorporate some unemployed) may be used as a proxy as was used by Wang, Wei and Liu (2010). In similar vein, we use the relative factor endowment measured as the ratio of capital stock to labour force. With respect to the size of market, or the economic mass variable, studies such as Helpman and Krugman (1985) and Hunter and Markussen (1988) confirm the increase in international trade consequent upon the convergence in income levels and use GDP as the economic mass (or market size). Thus, a positive relationship is expected between GDP and bilateral trade flows. However, in the spirit of Baldwin and Taglioni (2011), when the role of intermediate goods is important, emphasis shifts to gross measures rather than value added measures like GDP. In this vein, a positive relationship is expected between gross output (proxy for economic mass variable) and intra-industry trade/intra-regional intermediate trade, but the fixed effects (time effects in this case) may be used to control for the economic mass which varies with time - this is in line with Baldwin and Taglioni (2007 \& 2011).

The role of intermediate tariffs, which is the variable of interest, cannot be over-emphasized as harped by proponents of value chains, be it regional or global. Proponents maintain that tariffs on intermediates that cross borders multiple times incur costs that increase in the number of times such intermediates cross borders (Lopez-Gonzalez, 2012). In essence, intra-regional intermediate trade flows is expected to be decreasing in intermediate tariffs. In the case of economic integration arrangements within a regional economic community, which in the case of ECOWAS are the West African Economic and Monetary Union (WAEMU) and the West African Monetary Zone (WAMZ), trade literature note the need to 'control' for them. These arrangements may be trade creating or trade diverting. Yet it is hypothesised that a positive relationship is expected between the presence of economic integration arrangements and intra-regional trade flows. Concerning the distance between trade partners, the standard gravity model (built on the Newtonian law of gravity) in itself predicts bilateral trade flows to decrease in geographical distance between the trading partners. Positive coefficients are expected for the quality of institution and infrastructure.

\subsection{Model specification}

To achieve the objective of this study, the model of interest is expressed as:

$$
\begin{aligned}
\ln \left(E X_{i j t}\right)= & \varphi_{0}+\varphi_{1} \ln \left(R L F_{i j t}\right)+\varphi_{2} \ln \left(G D P S I M_{i j t}\right)+\varphi_{3} \ln \left(I M D T_{i t} \cdot I M D T_{j t}\right)+\varphi_{4} C O N T I G_{i j}+\varphi_{5} C O M L_{i j}+\varphi_{6} \ln \left(D I S_{i j}\right)+ \\
& \varphi_{7} W A E M U_{i j t}+\varphi_{8} W A M Z_{i j t}+\varphi_{9}\left(I N S T_{i t} I N S T_{j t}\right)+\varphi_{10} \ln \left(I N F R_{i t} \cdot I N F R_{j t}\right)+U_{i j t}
\end{aligned}
$$

where $\mathrm{EX}=$ intermediate export; $\mathrm{RLF}=$ absolute difference in relative factor endowments; GDPSIM $=$ similarity of GDP measured as

$S I M_{i j t}=1-\frac{G D P_{i t}^{2}}{\left(G D P_{i t}+G D P_{j t}\right)^{2}}-\frac{G D P_{j t}^{2}}{\left(G D P_{i t}+G D P_{j t}\right)^{2}} ;$ IMDT $=$ intermediate tariff faced by exports; CONTIG $=$ contiguity/adjacency which is a dummy that takes the value 1 if partners share a common border and 0 otherwise; $\mathrm{COML}=$ common language which takes the value 1 if partners have a common official language and 0; DIS = distance between the two countries; WAEMU = dummy variable which takes the value 1 if both partners belong to the West African Economic and Monetary Union, also known as UEMOA (countries here are Benin, Burkina Faso, Cote d'Ivoire, Guinea Bissau, Mali, Niger, Senegal and Togo) and 0 otherwise; WAMZ = dummy variable which takes the value 1 if both partners belong to the West African Monetary Zone (these countries are Nigeria, The Gambia, Ghana, Guinea and Sierra Leone) and 0 otherwise. The sign of the coefficient on these dummies are meant to account for elements of trade creation or diversion. It is expected that other factors held constant, increased intraregional flows would 
increase with increased flows in these economic integration arrangements. Thus a negative coefficient on any of these variables indicate trade diversion while a positive coefficient indicates trade creation within ECOWAS; INST $=$ quality of institution ${ }^{1}$; INFR $=$ quality of infrastructure; $\mathrm{U}=$ idiosyncratic error.

It is to be noted that in the basic gravity model, the economic mass is deflated by the 'multilateral resistance term.' However, here, we allow the time-varying fixed effects to capture both the economic mass (demand and supply conditions) and the multilateral resistance term, both of which vary over time. For the quality of institution which is to be included in the auxiliary regression, rather than use a narrow definition of the quality of institution, a principal component analysis is conducted to derive a composite index. The variables subjected to PCA are: voice and accountability, political stability, government effectiveness, regulatory quality, control of corruption and rule of law. The criteria for concluding in favour of the PCA include that: (1) The Eigenvalue of that component should be greater than or equal to 1. (2) The principal component must account for at least 60 percent of the variance in the entire series. (3) The test should pass the Kaiser-Meyer-Olkin (KMO) measure of sampling adequacy, a measure which lies between 0 and 1 . Specifically, the value should be greater than 0.70 . Small values depict that the variables do not have much in common to warrant a principal component analysis. Kaiser (1974) gave the following labels: 0.00 to 0.49 - unacceptable; $0.50-0.59$ - miserable; 0.60-0.69- mediocre; 0.70-0.79 - middling; 0.800.89 - meritorious, and 0.90-1.00 - marvellous. The principal component analysis test yielded a positive result for the quality of institution. For instance, the Kaiser-Meyer-Olkin (KMO) overall measure of adequacy gave a value around 0.85, similar to the results of Inegbedion and Obadiaru (2018), which falls in KMO's 'meritorious' range. But the quality of infrastructure fails the PCA test and rather than adopt a narrow definition for this variable, it is not included in the empirical estimations.

In respect of the technique of estimation, the common issues in estimating bilateral gravity models include the preponderance of zero trade flows (including zeros for some regressors), sample selection bias as noted by Heckman (1979) and endogeneity as a result of omitted variables or reverse causation (such as between RTAs or economic integration arrangements and trade flows), among others. Considering the peculiar nature of the ECOWAS bilateral intermediate export flows, more than 40 percent of the total intermediate exports are zeros. Simply adopting a technique such as truncated OLS or censoring leads to reduction in efficiency as a result of loss of information - this may bias the estimates due to the omission of data (Estrella, 2012). Westerlund and Wilhemson (2009) also noted that elimination of the zero trade flows in the event that they are not distributed randomly would result in selection bias. Zero trade flows may also be as a result of the affinity (or lack of it) of some countries for the products of other countries. These suggest checking for the significance or not, of selection bias, using the Heckman Two-step technique. But an exclusion variable is needed to identify the parameters on both the Probit (first step) and Heckman Two-step equations.

We follow an alternative to the use of a given variable as an exclusion variable - this was proposed by Linders and de Groot (2006). In line with Linders and de Groot (2006), Haq, Meilke and Cranfield (2010) included the same set of variables in both equations while allowing the normality of the error in both equations to help with the identification of parameters. It is to be noted that for the first step, i.e. the Probit/selection model, fixed effects are not included. For comparison, an alternative technique of estimation- Poisson Pseudo Maximum Likelihood (PPML) will be used. The PPML technique is suggested in the literature (such as the work of Santos \& Tenreyro, 2006) to handle such issues as heteroskedasticity. Santos and Tenreyro (2006) noted that when the gravity equation is log-linearised, the property of the error term is changed and the estimates become inefficient in the presence of heteroskedasticity.

\footnotetext{
1 The quality of institution is not logged here because it is an index ranging between -2.5 and 2.5
} 
Heteroskedasticity essentially alters the true variances (not the coefficients) thus leading to biased $\mathrm{t}$ statistics. PPML does not log-linearise the trade flows and so avoids the shortcoming of log-linearisation. The time-varying importer and exporter fixed effects are also counted upon to mitigate the possibilities of reverse causations and are included for both Heckman Two-step and PPML.

\subsection{Sources of data}

The data on Guinea Bissau for the variables of interest are sparse, hence the country is excluded from the analysis while the other 14 countries are included. All the financial variables are measured in current million dollars and not deflated by US' consumer price index (as commonly done) to avoid Baldwin and Taglioni's (2007)'s 'gold error.' The scope of the study is 2000 to 2015; 2015 being the most recent year for which data can be obtained for most of the ECOWAS countries. The choice of 2000 as the start year follows from the reasoning that this corresponds to10 years after the introduction of the ECOWAS Trade Liberalisation Scheme (ETLS) which was put in place in 1990. It is expected that tariff and non-tariff barriers to trade within this regional economic community should have been cleared 10 years after the introduction of ETLS. Data on intermediate tariffs (AHS weighted average) and intermediate exports were obtained from World Integrated Trade Solutions Trains Database; GDP similarity - ECOWAS National Accounts; Quality of institution and infrastructure - Worldwide Governance Indicators; WAEMU and WAMZ- Available on their websites.

\section{EMPIRICAL RESULTS AND DISCUSSION}

Table 1 presents the summary statistics. The summary statistics, among other information it conveys, shows that the variables have low standard deviation and the maximum values show that there are no outliers that can negatively influence the outcomes of the regression analysis. The dependent variable logged intraregional intermediate exports (LEX) has fewer observations because of the prevalence of zero trade values.

Table 1

Summary statistics

\begin{tabular}{|c|c|c|c|c|c|}
\hline Variable & Obs. & Mean & Std. Dev. & Min & Max \\
\hline LEX & 1575 & -.8816576 & 3.134887 & -11.8696 & 6.689053 \\
\hline LRLF & 2521 & 8.807427 & 7.226629 & -5.115104 & 23.31332 \\
\hline LGDPSIM & 2912 & -.4720949 & 1.611785 & -16.84518 & .6916826 \\
\hline LIMDT & 2912 & .949894 & 896535 & 0 & 6.879187 \\
\hline CONTIG & 2912 & .2527473 & .4346619 & 0 & 1 \\
\hline COML & 2912 & .4179258 & .4933025 & 0 & 1 \\
\hline WAEMU & 2912 & .2304258 & .4211777 & 0 & 1 \\
\hline WAMZ & 2912 & .1102335 & .3132344 & 0 & 1 \\
\hline LDIS & 2912 & 7.048401 & 6044909 & 5.238067 & 8.119218 \\
\hline INST & 2912 & -.3133891 & 4.185296 & -21.34308 & 15.5987 \\
\hline
\end{tabular}

Source: Authors', using STATA software.

Table 2 presents the empirical estimates using the Heckman Two-step and PPML techniques.

Considering the sign on the variable of interest- intermediate tariff, the Heckman technique outperforms $\mathrm{PPML}^{2}$ in predicting its sign. In what follows, the estimates from Heckman are used in

\footnotetext{
2 Varying the cross-section and time series dimensions and experimenting with the feasible generalized least square, least square dummy variable and systems GMM techniques, the Heckman Two-step still showed better fit than all of them. This suggests the better ability of the Heckman Two-step technique to handle estimations when zero trade flows are numerous.
} 
interpretation. The better performance of Heckman in predicting trade flows in this current study is supported by the finding of Estrella (2012) who used a dataset covering 80 percent of world trade and observed that Heckman sample selection model performs better, overall, than other techniques, for the gravity equation specified by that study.

Table 2

\begin{tabular}{|c|c|c|c|}
\hline \multicolumn{4}{|c|}{ Empirical results } \\
\hline \multirow{2}{*}{$\begin{array}{l}\text { Dep. Var. } \\
\text { LEX }\end{array}$} & \multicolumn{2}{|c|}{ Heckman } & \multirow{2}{*}{ PPML } \\
\hline & Selection & Two-Step & \\
\hline Regressors & $(1)$ & $(2)$ & (3) \\
\hline LRLF & $\begin{array}{c}0.02499^{* * * *} \\
(0.004)\end{array}$ & $\begin{array}{c}-0.09531^{*} \\
(0.051)\end{array}$ & $\begin{array}{c}-0.06218 \\
(0.050)\end{array}$ \\
\hline LGDPSIM & $\begin{array}{c}-0.00829 \\
(0.017)\end{array}$ & $\begin{array}{c}0.74362^{* * * *} \\
(0.070)\end{array}$ & $\begin{array}{c}1.04428^{* * *} \\
(0.075)\end{array}$ \\
\hline LIMDT & $\begin{array}{c}7619.94 \\
-\end{array}$ & $\begin{array}{c}-0.04931 \\
(0.049)\end{array}$ & $\begin{array}{c}0.09985^{\text {*** }} \\
(0.026)\end{array}$ \\
\hline CONTIG & $\begin{array}{c}0.28739^{* * *} \\
(0.1060\end{array}$ & $\begin{array}{c}1.32966^{* * * *} \\
(0.167)\end{array}$ & $\begin{array}{c}1.03933^{* * *} \\
(0.144)\end{array}$ \\
\hline COML & $\begin{array}{c}-0.04762 \\
(0.089)\end{array}$ & $\begin{array}{c}-0.60534^{* * *} \\
(0.240)\end{array}$ & $\begin{array}{c}-0.86398^{* * * *} \\
(0.388)\end{array}$ \\
\hline LDIS & $\begin{array}{c}-0.12582^{*} \\
(0.070)\end{array}$ & $\begin{array}{c}-0.66445^{* * *} \\
(0.127)\end{array}$ & $\begin{array}{c}-0.47408^{* * *} \\
(0.122)\end{array}$ \\
\hline WAEMU & $\begin{array}{c}1.09209^{* * * *} \\
(0.118)\end{array}$ & $\begin{array}{c}1.05413^{* * *} \\
(0.294)\end{array}$ & $\begin{array}{c}1.93517^{* * *} \\
(0.393)\end{array}$ \\
\hline WAMZ & $\begin{array}{c}0.67785^{* * *} \\
(0.109)\end{array}$ & $\begin{array}{c}0.44922 \\
(0.287)\end{array}$ & $\begin{array}{c}0.49993 \\
(0.442)\end{array}$ \\
\hline INST & $\begin{array}{c}0.00309 \\
(0.008)\end{array}$ & $\begin{array}{c}0.02475 \\
(0.017)\end{array}$ & $\begin{array}{c}0.01244 \\
(0.016)\end{array}$ \\
\hline CONSTANT & $\begin{array}{c}0.12301 \\
(0.508)\end{array}$ & $\begin{array}{c}5.0006^{* * * *} \\
(1.340)\end{array}$ & $\begin{array}{c}4.35568^{* * *} \\
(1.084)\end{array}$ \\
\hline Inverse Mills Ratio & ( & $\begin{array}{c}-0.46076 \\
(0.281)\end{array}$ & $\mathrm{C}_{2}$ \\
\hline Exporter-year Fes & No & Yes & Yes \\
\hline Importer-year Fes & No & Yes & Yes \\
\hline Observations & - & 2521 & 2521 \\
\hline No. of countries & 14 & 14 & 14 \\
\hline Wald chi-squared(F-Stat) & - & 2857.36 & 45003.77 \\
\hline R-squared & - & - & 0.80 \\
\hline Chi-squared [p-value] & - & {$[0.0000]$} & {$[0.0000]$} \\
\hline
\end{tabular}

Notes: For PPML, the dependent variable is EX and not its log.

Robust standard errors, consistent in the presence of any pattern of heteroskedasticity and autocorrelation within panels are reported in curly brackets. p-values are presented in square brackets. *,** and ${ }^{* * *}$ respectively indicate significance at $10 \%, 5 \%$ and $1 \%$ levels.

Before proceeding, the Heckman Two-step ${ }^{3}$ yields correct signs for all the variables with the exception of common language. PPML also yields a wrong sign for common language. It is also worth noting that there is agreement in the conclusion drawn from both techniques about the applicability of the

${ }^{3}$ The estimated Inverse Mills ratio (selection bias) is insignificant because of the appropriate use of the time-varying fixed effects. Auxiliary regressions (not reported here) using different choice of fixed effects yield significant Inverse Mills ratio. 
new trade theory (NTT) to the trade in intermediate goods in ECOWAS. It may be recalled that the coefficient on the differences in relative factor endowments (LRLF) (proxied by capital-labour intensity) and the similarities in GDP lend credence to the ability of NTT to explain an intra-industry trade type in which a country can simultaneously import and export similar goods or services, say goods that may even belong to the same sector rather than in different sectors as predicted by theory of inter-industry trade.

From the estimates, the coefficient on the relative factor endowment (LRLF) and GDP similarity (LGDPSIM) both follow the prediction of NTT as the former picks up a negative sign while the latter has a positive sign. Within ECOWAS, Cape Verde, which has the highest capital-labour force ratio (and GDP per capita, in the situation GDP per capita is used as a proxy for relative factor endowment) can engage in trade in intermediates with countries with relatively low capital-labour force ratio such as The Gambia, Liberia and Sierra Leone; an absolute difference of about 1300 percent points between the highest and the lowest values in ECOWAS.

When the similarity in factor endowments or intensities increases by 100 percent, the flows of intermediate exports decline by about 9.5 percent. This finding is in contrast to that of Afolabi et al. (2015) who used the difference in per capita income as a proxy for difference in relative factor endowments and obtained a positive and significant coefficient while assessing regionalism and ECOWAS trade performance using a gravity approach. However, it is similar to that of Wang, Wei and Liu (2010) who investigated the determinants of trade flows in OECD countries using gravity panel data models and obtained a negative but significant estimate for the relative factor endowment. For the similarity in GDP (LGDPSIM), it has a correct sign and statistically significant irrespective of the technique being considered. The positive sign of this variable shows that the more similar ECOWAS countries are in GDP, the higher the trade in intermediate goods. Thus, within ECOWAS, similarity in GDP is more a significant driver of the exports of intermediate goods than differences in factor endowments.

The key variable of interest is a continuous trade policy variable - tariff on intermediate goods (LIMDT). This variable has a correct sign but not a significant driver of intermediate exports in ECOWAS. A 100 percent increase in tariff on intermediate goods results on the average to about 4.9 percent decline in the export of intermediate goods in the ECOWAS sub-region. Other similar studies on ECOWAS did not consider the role of intermediate tariffs so the result from this current study cannot be compared to any of those studies. The negative but insignificant impact of intermediate tariffs on intermediate exports within the sub-region implies that intermediate tariff is not sufficiently low as to significantly bolster intermediate exports within ECOWAS. This finding challenges the performance of The ECOWAS Trade Liberalisation Scheme (ETLS) as ETLS, according to ECOWAS Vanguard (2013) was aimed at progressively reducing and later eliminating all tariff and non-tariff barriers against intraECOWAS trade (ECOWAS Vanguard, 2013).

It is expected that since ETLS was fully implemented in 1990, its impact in this area of tariff reduction should have been significantly felt 10 years after, which means year 2000 upwards, which is the scope of this study. As earlier noted, statistics from WITS reveals the disparities in charges on intermediate goods within the sub-region with The Gambia being the 'most hostile' in terms of intermediate tariff charged and Nigeria being the country that faces the most tariff charges on intermediate goods, at least within the study period. The finding that intermediate tariffs charged is not a significant driver of the flow of intermediate goods within the sub-region suggests the need for the ECOWAS REC to look inwards and address the disparate and unsupportive tariff policies within the region so as to further encourage intra-regional trade flows.

The gravity theory of trade posits that contiguity enhances trade. From the estimates, this assertion holds true as contiguity positively and significantly impact intermediate exports within the sub-region. The coefficient shows that countries that are close to one another tend to engage more heavily in trade than otherwise. For the common language variable, the point estimate is contrary to a priori expectation. 
Although the existence of a regional economic community (REC) should lower barriers including language bias to trade within the sub-region, it is not expected that sharing the same official language should negatively and significantly retard intermediate trade flows. The estimate of distance is both economically and statistically significant. The statistical significance of distance implies that it is a significant determinant of intermediate trade flows within ECOWAS.

Coming to the roles of economic integration agreements within ECOWAS, for the francophone dominated agreement (WAEMU ${ }^{4}$ ), it positively and significantly drives intermediate exports in ECOWAS even at the 1 percent level of significance irrespective of the technique of analysis considered. Thus, it may be concluded that WAEMU is trade creating. More explicitly, the positive coefficient on the WAEMU variable in respect of intermediate exports implies that the existence of WAEMU does not jeopardize the total intermediate export flows between the members of WAEMU and ECOWAS at large. The presence of WAMZ (Anglophone dominated agreement) is also trade creating as it positively impacts intermediate exports, albeit to a statistically insignificant degree. On the average, WAMZ increases intra-ECOWAS trade flows by about 57 percent $\left(e^{0.45}-1=0.57\right)$ but insignificantly even at the 10 percent level.

The quality of institution within the sub-region picks up the correct (positive) sign but it is statistically insignificant. Garnering insights from the Worldwide Governance Indicators' (WGI) database, most of the indicators of the quality of institution in ECOWAS are negative (on a scale of -2.5 to 2.5) when averaged over the scope of the study, i.e. between 2000 and 2015. From the WGI database, only Cape Verde recorded three positive values out of the six indicators of the quality of institution subjected to the principal component analysis (voice and accountability, political stability, control of corruption, governance effectiveness, regulatory quality and rule of law). Other countries have at least two negative figures, with most recording three, four or more negatives for these indicators.

\section{CONCLUSION}

The new trade theory explains intermediate exports in ECOWAS and the empirical estimates show that intermediate tariffs do not significantly impact intra-regional intermediate exports. The significant determinants of intra-regional intermediate exports in ECOWAS are the gravity variables, similarity in GDPs and the WAEMU trade agreement while intermediate tariffs, the WAMZ trade agreement and the quality of institution are not significant determinants of intra-regional intermediate exports in ECOWAS. The insignificance of intermediate tariffs suggest that tariffs charged on intermediates within ECOWAS do not bode well for trade integration, particularly in intermediate goods. The finding in respect of the insignificance of intermediate tariffs challenges the performance of such ECOWAS initiatives as ETLS. Regional efforts should synergise with national efforts to make trading within ECOWAS cheaper. This is expected to be a step in the right direction in the drive towards a continental free trade area and in building resilient value chains within ECOWAS. National economies such as The Gambia and Benin who levy relatively high charges on intermediates (as compared with countries like Senegal and Cape Verde) should be encouraged to consider reviewing their charges on other Member States downwards in order to foster increased trade in intermediates within the region.

In addition, it may be recalled that the quality of institution is a composite index comprising six indicators - voice and accountability; political stability; governance effectiveness; regulatory quality; control of corruption; and the rule of law. The quality of institution may deter or enhance trade. The

${ }^{4}$ Following Baier and Bergstrand (2007) and Baier, Bergstrand and Feng (2013), an exogeneity test for WAEMU and WAMZ showed that they both are exogenous. The exogeneity tests are available upon request. 
absence of violence and terrorism and political instability stimulates both domestic and foreign interests in trade. Government effectiveness shows the quality of the formulation of policies and how credible the government is in respect of commitment to such policies. Policy inconsistencies portend negative effects for both private and public participation in trade. Regulatory quality shows the ability to formulate and implement sound policies supportive of the development of the private sector. Weakness in this area tends to retard the participation of the private sector in business and trade. The rule of law shows the degree of compliance of citizenry to societal rules and particularly the quality of contract enforcement, property rights, police and the courts, and the propensities for crime and violence. Obviously, a weak rule of law is detrimental to interests and participation in trade, be it national, regional or global. From Worldwide Governance Indicators' database, in 2015 amongst the ECOWAS Member States, Nigeria had the lowest (worst) score in political stability with a score of -1.93 (on a scale of -2.5 to 2.5). In terms of government effectiveness, regulatory quality and rule of law in 2015, Liberia, Sierra Leone and Guinea had the lowest score of $-1.39,-0.90$ and -1.16 in respective indicators. National governments need dogged and sincere commitments to turn the negatives recorded in these indicators around. ECOWAS may initiate incentives to reward Member States who significantly improve their rankings in these indicators in order to encourage others who lag behind and enhance trade ties within the region and by extension regional value chains.

\section{ACKNOWLEDGEMENT}

The contributions of Landmark and Covenant Universities, the sponsors of the Ph.D. thesis of the lead author, out of which this paper was extracted, are highly appreciated. The comments of the anonymous reviewers are also valued.

\section{REFERENCES}

African Trade Policy Centre, Economic Commission for Africa \& African Union Commission. (2018). African Continental Free Trade Area: Questions and answers. Retrieved August, 2018 https://au.int/sites/default/files/documents/33984-doc-qa_cfta_en_rev15march.pdf

African Development Bank, OECD, and UNDP. (2014). African Economic Outlook 2014: Global Value Chains and Africa's Industrialisation. Paris: AfDB, OECD, UNDP.

Afolabi, L. O., Nor Aznin, B., \& Mukhriz, I.A. (2015). Regionalism and ECOWAS trade performance: A gravity model approach. Boğariçi Journal Review of Social, Economic and Administrative Studies, 29 (2), 59-71.

Anderson, J.E. (1979). A theoretical foundation for the gravity equation. American Economic Review, 69, 106116.

Baier, S. L., \& Bergstrand, J. H. (2007). Do free trade agreements actually increase members' international trade? Journal of International Economics, 71, 72-95.

Baier, S. L., Bergstrand, J. H., \& Feng, M. (2013). Economic integration agreements and the margins of international trade. https://www3.nd.edu/.../Baier $\% 20$ Bergstrand $\% 20 \mathrm{Feng} \% 20 \mathrm{Margins} \%$ 20and\%20EIAs.p

Baldwin, R., \& Taglioni, D. (2007). Gravity for dummies and dummies for gravity Equations. NBER WP 12516, published as "Trade effects of the euro: A comparison of estimators". Journal of Economic Integration, 22(4), 780-818.

Baldwin, R., \& Taglioni, D. (2011). Gravity chains: Estimating bilateral trade flows when parts and components trade is important. Germany: European Central Bank.

ECOWAS Vanguard (2013). The ECOWAS Trade Liberalisation Scheme: Genesis, conditions and appraisal. NANTS Regional Trade Advocacy Series, 2(3).

Estrella, G. H. (2012). Comparing alternative methods to estimate gravity models of bilateral Trade. Empirical Economics, 44, 1087-1111.

Helpman, E., \& Krugman, P.R. (1985). Market Structure and Foreign Trade. Cambridge: MIT Press. 
Kaiser, H. F. (1958). The varimax criterion for analytic rotation in factor analysis. Psychometrika, 23(3), 187200.

Kowalski, P., Lopez-Gonzalez, J., Ragoussi, A., \& Ugarte, C. (2015). Participation of Developing Countries in Global Value Chains: Implications for Trade and Trade-Related Policies. OECD Trade Policy Papers, No. 179. Paris: OECD Publishing. http://dx.doi.org/10.1787/5js33lfw0xxn-en

Haq, Z., Meilke, K., \& Cranfield, J. (2010). Does the gravity model suffer from selection bias?. Canadian Agricultural Trade Policy Research Network Working Paper no 90884.

Heckman, J. J. (1979). Sample selection bias as a specification error. Econometrica 47, 153-61.

Inegbedion, H. E., \& Obadiaru, E. D. (2018). Modelling factors that influence brand loyalty in the Nigerian telecommunications industry. Journal of Strategic Marketing. doi:1080/0965254X

Linders, G. M., \& de Groot, H. (2006). Estimation of the gravity equation in the presence of zero flows. Tinbergen Institute Discussion Papers 06-072/3.

Lopez-Gonzalez, J. (2012). The impact of free trade agreements on vertical specialisation. Working Paper No. 2012/36, Swiss National Centre of Competence in Research, Bern.

Obasaju, B. O., Olayiwola, W.K., \& Okodua, H. (2016). Regional economic integration in West Africa and cocoa beans value chain in Nigeria. Conference Proceedings of the 27th International Business Information Management Association (IBIMA) Conference, Milan, Italy, 4th - 5th of May 2016.

Olofin, S., Salisu, A., Ademuyiwa, I., \& Owuru, J. (2013). Determinants of a successful regional trade agreement in West Africa. www.crepol.org/images/my_pdf/july-paper-02.pdf

Santos Silva, J. M. \& Tenreyro, S. (2006). The Log of Gravity. Review of Economics and Statistics, 88, 641-658.

Sapkota, J.B., Acharya, C.P., Minowa, M., \& Neupane, P. (2018). Trade integration in Asia: Trends and determinants. Journal of International Studies, 11(3), 271-283. doi:10.14254/2071-8330.2018/11-3/21

Slany, A. (2017). The role of trade policies in building regional value chains - some preliminary evidence for Africa. UNCTAD Research Paper No. 11.

Wang, C., Wei, Y. \& Liu, X. (2010). Determinants of bilateral trade flows in OECD Countries: Evidence from gravity panel data models. The World Economy, 33(7), 894-915.

Westerlund, J. \& Wilhelmsson, F. (2009). Estimating the gravity model without gravity using panel data. Applied Economics, 43, 641-649. 